\title{
Corrigendum: Functional Activation in the Ventral Object Processing Pathway during the First Year
}

\author{
Teresa Wilcox * and Marisa Biondi \\ Infant Cognition Lab, Department of Psychology, Texas A\&M University, College Station, TX, USA
}

Keywords: infants, object processing, object processing pathway, ventral temporal cortex, cortical development

\section{A corrigendum on}

Functional Activation in the Ventral Object Processing Pathway during the First Year by Wilcox, T., and Biondi, M. (2016). Front. Syst. Neurosci. 9:180. doi: 10.3389/fnsys.2015.00180

Table 3 of the Wilcox and Biondi (2016) article contained the incorrect $p$-values, which we hereby rectify. The original table contained two-tailed $p$-values rather than one-tailed $p$-values. The legend of Table 3 indicated that one-tailed values were reported. We therefore re-submit Table 3 with the correct one-tailed $p$-values.

\section{OPEN ACCESS}

Edited and reviewed by: Natasha Sigala,

University of Sussex, UK

${ }^{*}$ Correspondence:

Teresa Wilcox

twilcox@tamu.edu

Received: 04 April 2016 Accepted: 18 April 2016

Published: 03 May 2016

Citation: Wilcox T and Biondi M (2016) Corrigendum: Functional Activation in the Ventral Object Processing Pathway during the First Year. Front. Syst. Neurosci. 10:38 doi: 10.3389/fnsys.2016.00038

\section{AUTHOR CONTRIBUTIONS}

TW contributed to the conception and design of the work, data analysis and interpretation, and manuscript preparation. $\mathrm{MB}$ contributed to data acquisition and interpretation, and manuscript preparation.

\section{REFERENCES}

Benjamini, Y., and Hochberg, Y. (1995). Controlling the false discovery rate: a practical and powerful approach to multiple testing. J. R. Statis. Soc. 57, 289-300. doi: 10.2307/2346101

Cohen, J. (1988). Statistical Power Analysis for the Behavioral Sciences, 2nd Edn. Hillsdale, NJ: Lawrence Earlbaum Associates.

Conflict of Interest Statement: The authors declare that the research was conducted in the absence of any commercial or financial relationships that could be construed as a potential conflict of interest.

Copyright (C) 2016 Wilcox and Biondi. This is an open-access article distributed under the terms of the Creative Commons Attribution License (CC BY). The use, distribution or reproduction in other forums is permitted, provided the original author(s) or licensor are credited and that the original publication in this journal is cited, in accordance with accepted academic practice. No use, distribution or reproduction is permitted which does not comply with these terms. 
TABLE 3 | Mean (SD) HbO responses for the young and old age groups of

Experiment 2.

Areas of Interest

Young (4-6 months) Old (10-13 months)

\begin{tabular}{llll}
\hline Region I & $M(S D)$ & $0.0271(0.0358)$ & $0.0132(0.0527)$ \\
& $t(d f)$ & $3.211(17)$ & $1.002(15)$ \\
& $p$-value & $0.0025^{\star *}$ & 0.116 \\
& Cohen's $d$ & 1.065 & 0.354 \\
\hline Region II & $M(S D)$ & $0.0250(0.0450)$ & $0.0078(0.0282)$ \\
& $t(d f)$ & $2.135(17)$ & $1.111(15)$ \\
& $p$-value & $0.024^{* *}$ & 0.142 \\
& Cohen's $d$ & 0.71 & 0.391 \\
\hline \multirow{2}{*}{ Region III } & $M(S D) 3$ & $0.0150(0.0312)$ & $-0.0016(0.0255)$ \\
& $t(d f)$ & $2.038(17)$ & $-0.252(15)$ \\
& $p$-value & $0.0285^{\star *}$ & 0.402 \\
& Cohen's $d$ & 0.68 & 0.089
\end{tabular}

One sample t-tests were used to compare mean responses at each of the three RO/s to zero. One-tailed $p$-values that passed the Benjamini-Hochberg (Benjamini and Hochberg, 1995) test are indicated by asterisks: ${ }^{*} p<0.05$; ${ }^{* *} p<0.01$; ${ }^{* \star \star} p<0.001$. Effect sizes as measured by Cohen's $d$ are also reported (Cohen, 1988). 